\title{
Communicative functions of Why-questions in parent-child interaction at home
}

\author{
Bova A
}

Institute of Argumentation, Linguistics and Semiotics, University of Lugano, Lugano, Switzerland

\section{Summary}

The present investigation has examined 3 to 6 year old children's "why" questions and their communicative functions in family conversations. Children's why questions included in thirty videorecordings of dinnertime interactions, held by Italian and Swiss families, were analyzed. In this investigation, the presence of two fundamental functions of children's why questions, argumentative and explanatory, were brought to light. When the parent's opinion is put into doubt, the children's why question triggers the beginning of an argumentative discussion. When the child does not put into doubt the parent's opinion, as it refers to an event considered already ascertained, the function of the why question is to solicit an explanation of its causes. Besides, the specific use of the children's why question as a way to request the burden of proof, by assuming a waiting position before accepting or putting in doubt the parental prescription, were observed. The results of this study provide a contribution to research on parent-child interaction, taking into particular consideration the crucial argumentative role played by children.

\section{Introduction}

In the last decades family studies have been mostly inspired by the paradigm of family communication (cf. Vangelisti, 2004), and a proper dialogue among family members has been considered as an indicator of positive family relations (cf. Beavers \& Hampson, 2000; Olson, 2000). 
Grounded on the research tradition aforementioned, this paper focuses on verbal interaction dynamics among family members and, more specifically, it aims to analyze a specific kind of question, namely the why-question, frequently asked by children to adults during everyday interactions. Drawing on the model of Critical Discussion (henceforth, CD) (van Eemeren \& Grootendorst, 2004), we will analyze a representative case study that well-describes and highlights the results obtained through the qualitative analysis of a wider corpus of data composed of 30 video-recordings of dinner table conversations of Italian and Swiss families.

\section{Materials and Methods}

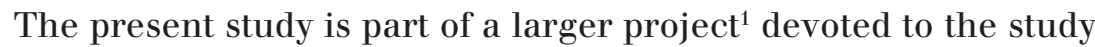
of argumentation in the family context. The general aim of the research is to verify the impact of argumentative strategies within the dynamics of family educational interactions. The research project is based on a corpus of 30 video-recorded dinner conversations (constituting about twenty hours of video data) of 5 Italian and 5 Swiss families (see Table 1). All participants are Italian-speaking.

In order to minimize researcher interferences, the recordings were performed by the families on their own. This means that dinner conversations are documented as they naturally happen, without the researchers imposing tasks or topics, orchestrating the spatial positioning of participants, or modifying the context. Each family videotaped their dinners four times over a four-week period. The length of the recordings varies from 20 to 40 minutes. In the first phase, all dinnertime conversations were fully transcribed ${ }^{2}$ using the CHILDES system (MacWhinney, 1989) and revised by two researchers until a high level of consent $(80 \%)$ was reached. This methodology allowed a detailed, veridical analysis of children's verbal interactions with all family members during the recording sessions. After this phase, the researchers jointly reviewed with the family members all the transcriptions at their home. This procedure made it possible to ask the family members to clarify some unclear passages (in the eyes of the researchers), e.g. implicit language, low level of recordings, and vague words and claims.

${ }^{1}$ I am referring to the Research Module "Argumentation as a reasonable alternative to conflict in family context" (project no. PDFMP1-123093/1) founded by the Swiss National Science Foundation. It is part of the ProDoc project "Argupolis: Argumentation Practices in Context," jointly designed and developed by scholars of the Universities of Lugano, Neuchâtel, Lausanne (Switzerland) and Amsterdam (The Netherlands).

${ }^{2}$ For the transcription symbols, see the Appendix. 
In order to analyze the function of children's why-questions within family conversations (through the application of the aforementioned criteria), we are going to present a representative case study of argumentative discussion among parents and children, which describes and highlights the results obtained through the qualitative analysis of the whole corpus of data of the research project. The example concerns a Swiss family. Fictitious names replace real names of participants, in order to ensure anonymity.

Excerpt 1: Family GEV, dinner 3; participants: MOM (mother, age: 32); DAD (father, age: 34); LUC (child 1, Luca, age: 9); BER (child 2, Bernardo, age: 4) All family members are eating, seated at the table.

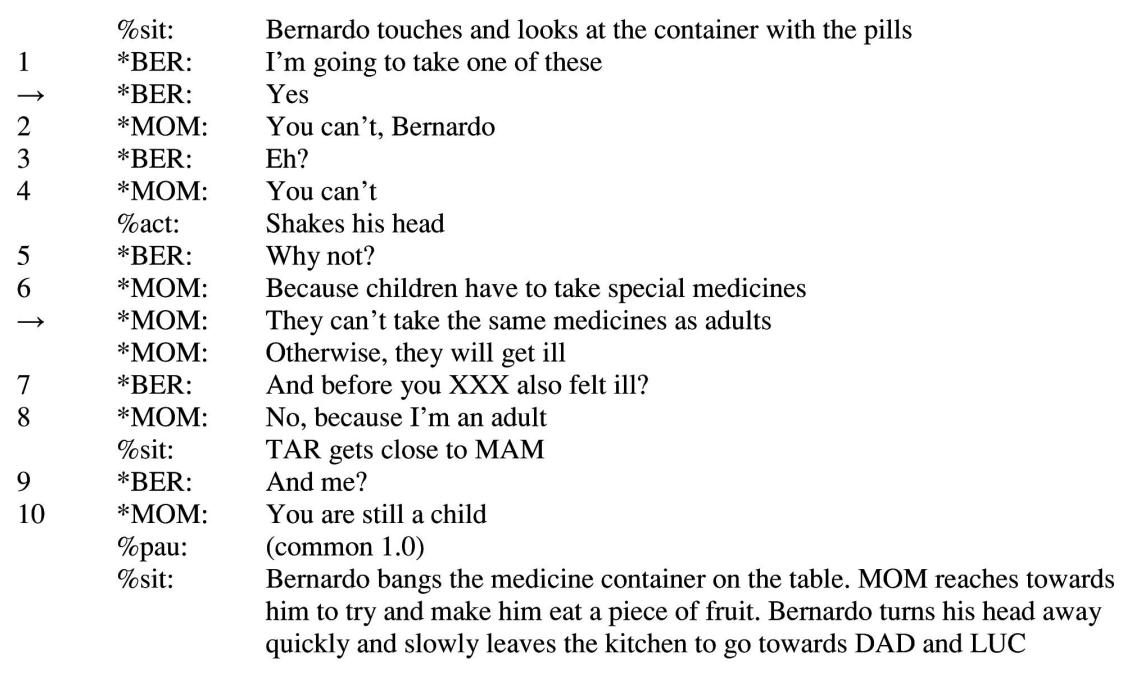

\section{Results}

In argumentative terms, we can now reconstruct the difference of opinion between the child and his mother in the following terms:

Coarguers: Mother and her child, Bernardo

Issue: Can Bernardo take the pills from the medicine container?

Type of difference of opinion: Single/Mixed

Mother's Standpoint: $\quad$ (a.) You can't take the medicines

Child's Standpoint: (b.) I want to take the pills from the medicine container

Mother's Argument: (1.) Because children have to take special medicines; (1.1) They can't take the same medicines as adults; (1.1.1) Otherwise they will get ill.

Within the selected sequence we intend to focus on two aspects. 
First, although the sequence starts because of the child's request ("I am going to take one of these [pills]"), it is the mother who assumes the burden of proof. In doing so, she is called upon to be the protagonist of the discussion and, accordingly, she provides arguments to defend her standpoint. Besides, as observed in other works devoted to the study of argumentative discussions in family (Bova, 2011), even though it is the child who want to start an argumentative discussion, it is a parental decision to open the real debate.

This aspect leads us toward the second important point we want to highlight in this analysis, and that more specifically addresses the issue at the basis of the present work, namely the function of the why-question asked by children. We have seen, in fact, that in turn 5 the child asks his mother the reason why he cannot take the pills that are in the medicine container. By asking why the child is thus stating that he wants to know the reason why he cannot take the medicines, and in doing so he makes clear to his mother that is putting into doubt her standpoint. This plainly put to the fore the function of the why-question as a modality to trigger the beginning of an argumentative discussion with his mother.

As already pointed out by Rocci (2009), the presence of significant argumentative indicators - "Why not?", "Because" - suggests that a critical discussion is taking place, i.e. an attempt to solve a disagreement "between a party who defends a certain standpoint, the protagonist, and a party who challenges this standpoint, the antagonist" (van Eemeren et al., 2007, p. 25). We do agree with Rocci when he states that the why-question is an argumentative indicator. What we want to add at this consideration is strictly linked to our context of analysis, i.e. the family. Indeed, within the everyday interactions during dinnertime, the why-question seems to be a specific "tool" through which the children manifest their desire to know the reason underneath parental prescriptions. As suggested by Ervin-Tripp and Strage (1985), parental prescriptions are frequently implicit or based on rules not initially known by children, and their strength and effectiveness depend mainly on parents' authority. In this perspective, it is very interesting to notice through the analysis of the excerpt we have presented that the why-question asked by the child produces the effect to elicit the explicitation of that rule on which the mother prohibition was based (children have to take special medicines, they can't take the same medicines as adults otherwise they will get ill).

Furthermore, he seems to make use of the why-questions in order to request the burden of proof, by assuming a waiting position before accepting or putting into doubt the parental prescription. Indeed, by using a why-question the child challenges the mother to justify her standpoint. The expression "waiting position" is frequently used 
in military slang to refer to a particular strategy used in war by naval units. A waiting position, in fact, is any suitable position in which naval units can be kept ready for operations at immediate notice. It goes without saying that the family context is not a battlefield, but by analogy, it seems that children ask why-questions in order to get into a waiting position, ready to accept or put into doubt the newly obtained information. Pragmatically speaking, it may be defined as a specific form of strategic maneuvering (van Eemeren, 2010) adopted by children in order to ask the other to justify their opinion.

\section{Conclusions}

In this study we focused on the children's why-question and its function during family dinner conversations. The method of analysis, i.e. the model of Critical Discussion (CD), has allowed a detailed investigation study of an argumentative sequence between a mother and her. The argumentative sequence taken into account for this study was selected within a wider corpus of data composed of 30 video-recordings of dinnertime interactions of Italian and Swiss families, insofar as it describes and highlights the results obtained through the analysis of the whole corpus of data of the research project.

At this juncture, it seems appropriate to take stock of the acquisitions of the study presented here, listing also the approximately drawn solutions that still need to be specified.

First, during the dinner conversations at home seems that is the parent who is called to begin an argumentative discussion in family, especially in order to justify a position, to provide arguments, to convince the child to accept an opinion. Second, regarding the function of the why question, the results of the qualitative analysis suggest that through the why-questions, children manifest their desire to know the reasons behind parents' prescriptions from a waiting position, ready to accept or put into doubt the new obtained information. This aspect puts into light the crucial function of the why-question asked by children during family conversations as a modality to trigger the beginning of an argumentative discussion.

\section{References}

BEAVERS, R., \& HAMPSON, R.B. (2000). The Beavers Systems Model of Family Functioning. Journal of Family Therapy, 22(2), 128-143.

BOVA, A. (2011). Implicitness functions in family argumentation. In F.H. van Eemeren, B. Garssen, D. Godden \& G. Mitchell (Eds.), Proceedings of the 7th Conference of the International Society for the Study of Argumentation (pp.149-161). Amsterdam: Rozenberg / Sic Sat. 
EEMEREN van, F.H. (2010). Strategic Maneuvering in Argumentative Discourse. Amsterdam: Benjamins.

EEMEREN van, F.H., \& GROOTENDOORST, R. (2004). A Systematic Theory of Argumentation: The Pragma-dialectical approach. Cambridge: Cambridge University Press.

EEMEREN van, F.H., HOUTLOSSER, P., \& SNOECK-HENKEMANS, A.F. (2007). Argumentative indicators in discourse. A pragma-dialectical study. New York: Springer.

ERVIN-TRIPP, S., \& STRAGE, A. (1985). Parent-Child Discourse. In T. van Dijk (Ed.), Handbook of Discourse Analysis. Vol. 3: Discourse and Dialogue (pp. 67-77). New York: Academic Press.

MACWHINNEY, B. (1989). The Child Project: computational tools for analyzing talk. Pittsburgh: Mellon University Press.

OLSON, D.H. (2000). Circumplex Model of marital and family systems. Journal of Family Therapy, 22(2), 144-167.

ROCCI, A. (2009). Modalities as Indicators in Argumentative Reconstruction. In F.H. van Eemeren \& B. Garssen (Eds.), Pondering on problems of argumentation (pp. 207-228). Dordrecht: Springer.

VANGELISTI, A.L. (Ed.). (2004). Handbook of family communication. Mahwah, NJ: Erlbaum. 